\section{A NOVEL MEDIUM FOR INCREASED CYTOTOXICITY AND SERUM-MINIMAL EX VIVO EXPANSION OF NATURAL KILLER (NK) CELLULAR IMMUNOTHERAPIES}

${ }^{1}$ Marc Gillig, 'Graeme Lambert, ${ }^{2}$ Matthew Forsberg, 'Donna Sonntag, 'Jason Cahoon, ${ }^{1}$ Rafet Amoor, ${ }^{1}$ Borom Chean, ${ }^{3}$ Lea Picard, ${ }^{3}$ Sabine Wingert, ${ }^{4}$ Caroline Hull, ${ }^{5}$ Jacki Kornbluth, ${ }^{3}$ Carsten Watzl, ${ }^{2}$ Christian Capitini, ${ }^{1}$ Rachit Ohri ${ }^{*} .{ }^{1}$ Enable Life Sciences LLC, Worcester MA; ${ }^{2}$ University of Wisconsin, Madison, Madison, WI USA; ${ }^{3}$ Leibniz Research Centre, Germany; ${ }^{4}$ Leucid Bio Ltd, London; ${ }^{5}$ St. Louis University

Background Despite significant clinical breakthroughs, ${ }^{1}{ }^{2}$ cellular immunotherapy remains unacceptably variable in performance $^{3}$ and impractically expensive for mainstream adoption. ${ }^{4}$ These hurdles are particularly true for new cancer immunotherapies with natural killer (NK) cells. Culturing NK cells ex vivo is challenging due to short half-lives, reduced functionality, and increased exhaustion. ${ }^{5}$ Also, the use of serum introduces inconsistency and increases cost. ${ }^{6}$ Here we introduce a novel prototype medium specifically formulated for NK cells, which uses a unique combination of plant extracts and molecular ingredients to increase cytotoxic performance while allowing the reduction of serum by up to 90 percent.

Methods KHYG-1 NK cell line, or primary NK cells, were brought to $2 \%$ or $2.5 \%$ serum, respectively, in the prototype media. DMEM/F12 with $20 \%$ serum (for KHYG-1) or $10 \%$ serum (for primary cells) was the control. All media was supplemented with $100 \mathrm{U} / \mathrm{mL}$ IL-2. Cell numbers were periodically assessed, using a cell counter or flow cytometry. For cytotoxicity assays, K562 target cells were cocultured with KHYG-1 cells (effector:target ratio 20:1) for 5h, or with primary NK cells $(4: 1)$ for $18 \mathrm{~h}$. Cells were stained with annexin $\mathrm{V}$ and propidium iodide to determine the levels of apoptosis and necrosis by flow cytometry. Levels of secreted proteins were determined using Luminex. Expression of CD56 was determined by flow cytometry.

Results Following adaptation to 2\% serum, growth of KHYG1 cells in the prototype media stayed nearly on pace with the control for over 3 weeks. Human primary NK cells grew 10fold over 10 days in the prototype media with 2.5\% serum, without feeder cells; in contrast, primary cells did not proliferate in control medium (figure 1). Beta testing confirmed that the prototype media improved the proliferation of primary NK cells over a 12-day period, relative to a gold standard medium (figure 2). After culture in prototype media, both KHYG-1 cells and primary NK cells exhibited higher cytotoxic activity toward K562 cells, compared with the activity of the same cells cultured in control medium (figure 3). Secretion of interferon-gamma, perforin, and granzyme A was increased in KHYG-1 cells cultured in prototype media (figure 4). Additionally, culture in this media pushes NK cells toward a more CD56-dim phenotype (figure 5), which is associated with increased cytotoxic activity.
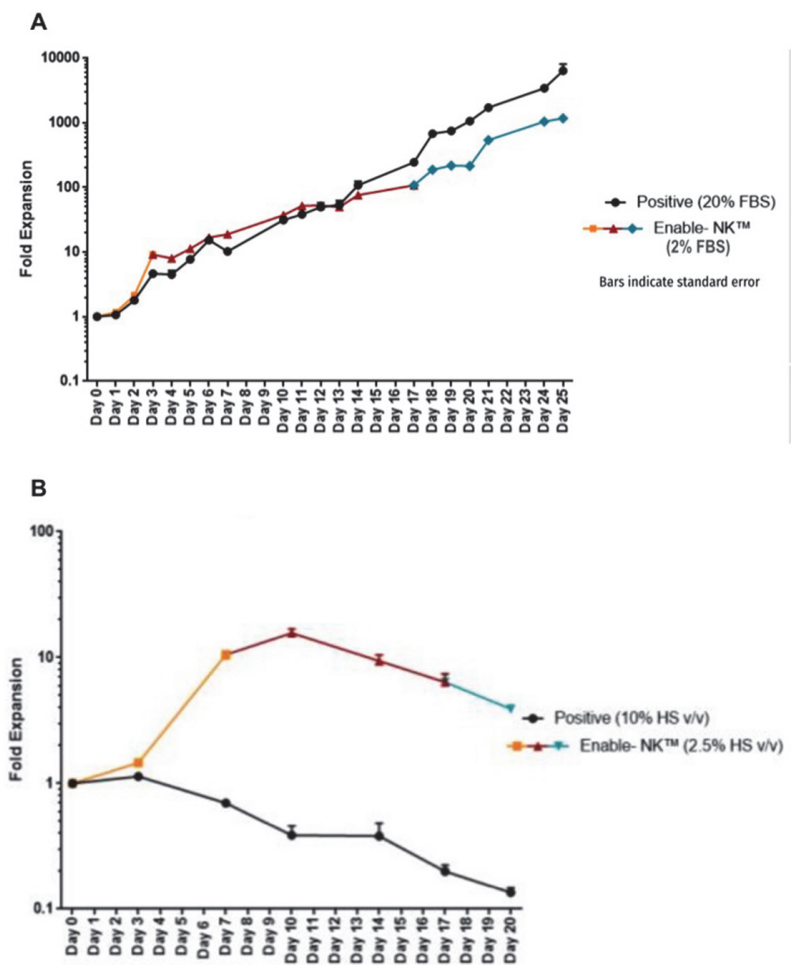

Abstract 210 Figure 1 Growth of NK cell line and human primary NK cells. (A) Growth of the KHYG-1 cell line, cultured in prototype media, kept pace with cells cultured in control medium. Orange indicates gradual adaptation to lower serum content; red indicates culturing in the formulation optimized for cell proliferation; blue indicates culturing in the formulation developed for NK cell activation. (B) Growth of primary NK cells was achieved in prototype media, but these cells did not grow in control medium. 
A
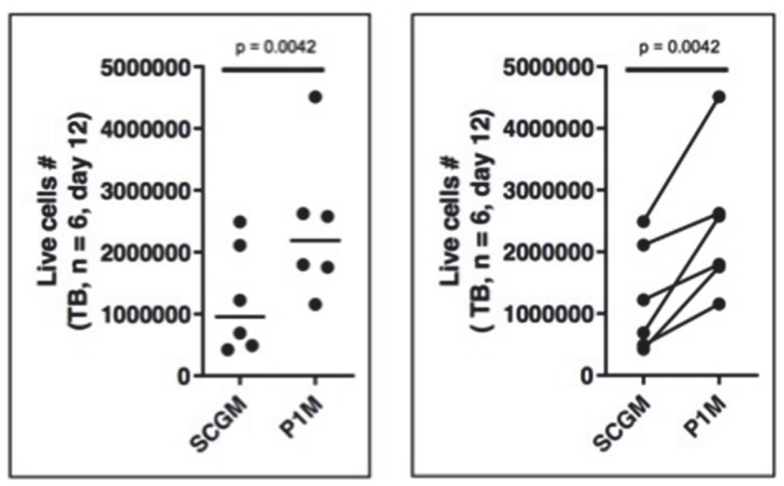

B

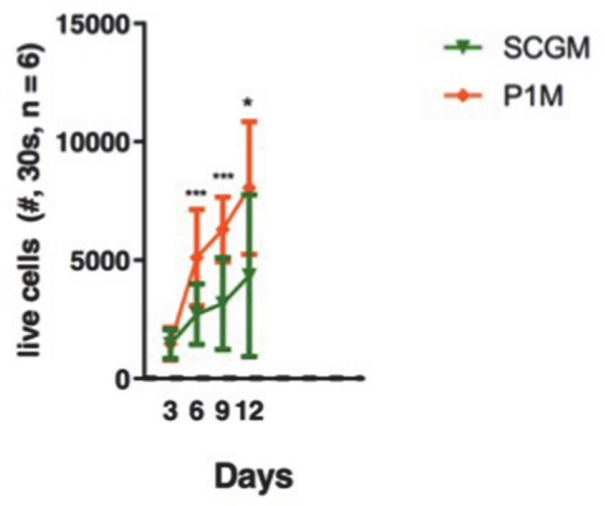

Abstract 210 Figure 2 Primary NK cells grow better in prototype media
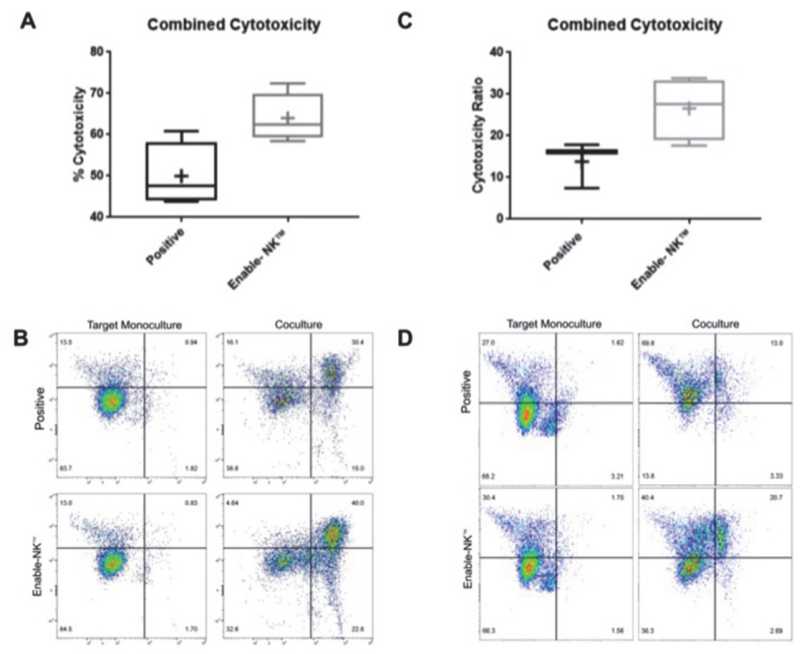

Abstract 210 Figure 3 NK cytotoxicity is enhanced by prototype media. (A and B) KHYG-1 cell line cocultured with K562 target cells. (C and D) Primary human NK cells cocultured with K562 target cells
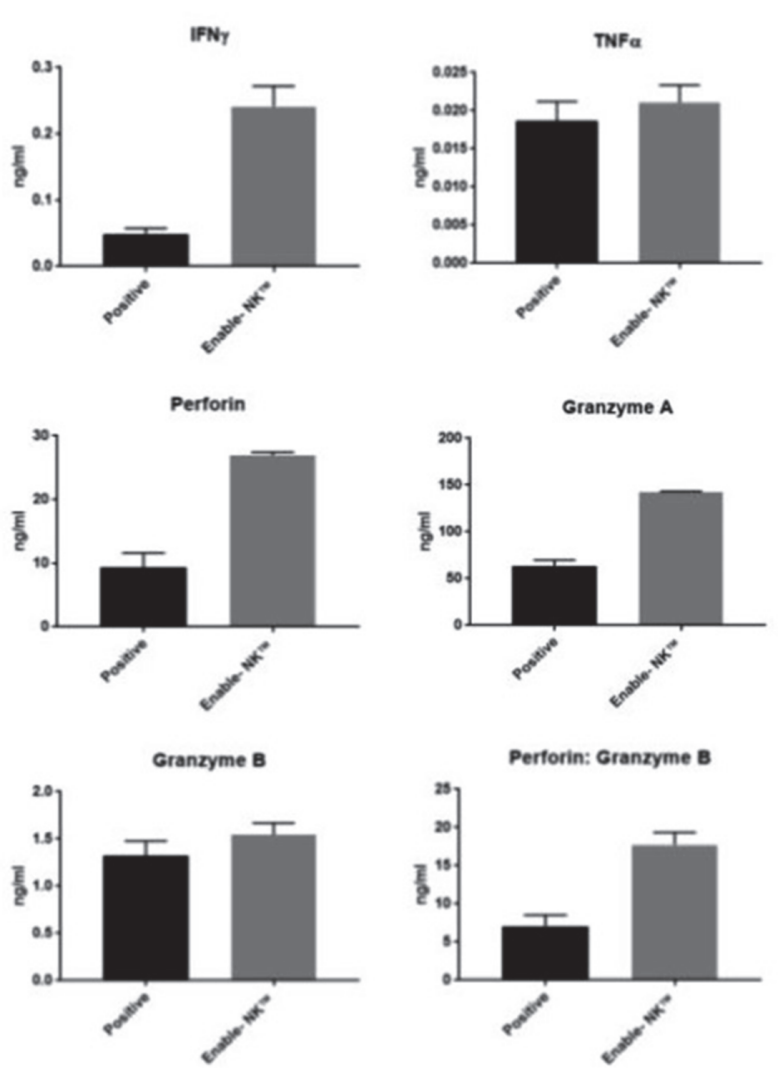

Abstract 210 Figure 4 Secretion of interferon, perforin, and granzyme $A$

A
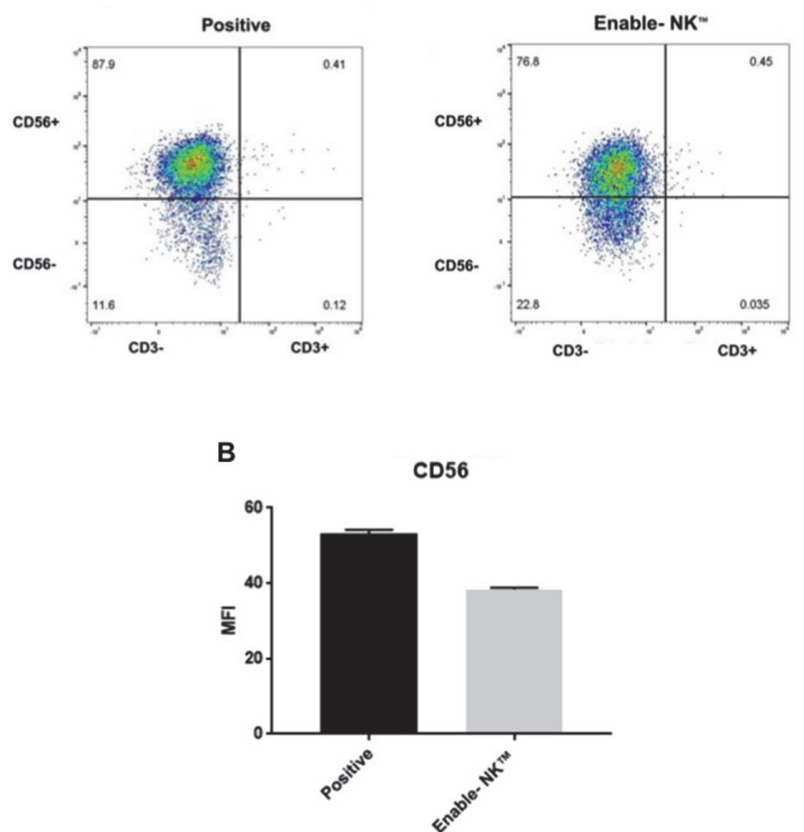

Abstract 210 Figure 5 Shift to CD56-dim phenotype 
Conclusions The prototype media increases the cytotoxic activity of NK cells against cancer cells. Also, it supports proliferation of NK cell lines and primary NK cells, even at reduced serum content.

\section{REFERENCES}

1. Hirayama AV, Gauthier J, Hay KA, Voutsinas JM, Wu Q, Pender BS, Hawkins RM, Vakil A, Steinmetz RN, Riddell SR, Maloney DG. High rate of durable complete remission in follicular lymphoma after CD19 CAR-T cell immunotherapy. Blood 2019;134(7):636-640.

2. Martinez VG, Park D, Acton SE. Immunotherapy: breaching the barriers for cancer treatment. Philos Trans R Soc B Biol Sci [Internet] Royal Society, 2019 August 19;374(1779):20180214. Available from: https://doi.org/10.1098/rstb.2018.0214

3. Burke C, Zylberberg C. Sources of variability in manufacturing of cell therapeutics. Regen Eng Transl Med 2019;5:332-40.

4. Leech AA, Neumann PJ, Cohen JT, Jagasia M, Dusetzina SB. Balancing value with affordability: cell immunotherapy for cancer treatment in the U.S. oncologist [Internet]. John Wiley \& Sons, Ltd, 2020 July 1;25(7):e1117-9. Available from: https://doi.org/10.1634/theoncologist.2020-0025

5. Fang F, Xiao W, Tian Z. Challenges of NK cell-based immunotherapy in the new era. Front Med [Internet], 2018;12(4):440-50. Available from: https://doi.org/ 10.1007/s11684-018-0653-9

6. Aijaz A, Li M, Smith D, Khong D, LeBlon C, Fenton OS, et al. Biomanufacturing for clinically advanced cell therapies. Nat Biomed Eng [Internet] 2018;2(6):36276. Available from: https://doi.org/10.1038/s41551-018-0246-6

http://dx.doi.org/10.1136/jitc-2021-SITC2021.210 